\title{
A Concise Route to MK-4482 (EIDD-2801) from Cytidine: Part 2
}

\author{
Gopalsamuthiram, Vijayagopal $^{\mathrm{a}}$; Williams, Corshai ${ }^{\mathrm{b}}$; Noble, Jeffrey ${ }^{\mathrm{a}}$; Jamison, Timothy F. ${ }^{\mathrm{b}}$; Gupton, B. \\ Frank ${ }^{\mathrm{a}}$; Snead, David R. ${ }^{\mathrm{a}, *}$ \\ AUTHOR ADDRESS
}

a) Medicines for All Institute, 737 N. $5^{\text {th }}$ St., Box 980100, Richmond VA, 23298-0100

b) Department of Chemistry, Massachusetts Institute of Technology, 77 Massachusetts Ave, Cambridge, Massachusetts, 02139

Supporting Information Placeholder

\begin{abstract}
A new route to MK-4482 (1) was developed. The route replaces uridine with the more available and less expensive cytidine. Low cost, simple reagents are used for the chemical transformations and the yield is improved from $17 \%$ to $44 \%$. A step is removed from the longest linear sequence, and these advancements are expected to expand access to MK-4482 should it become a viable drug substance.
\end{abstract}

MK-4482 (EIDD-2801) is an antiviral with emerging potential to treat COVID-19. ${ }^{1}$ If the drug candidate shows clinical efficacy, its structural simplicity and potential to be manufactured from abundant raw materials are features of great advantage toward provision of a widely accessible coronavirus treatment.

The initially disclosed synthetic route requires improvement, however. ${ }^{2}$ The API is constructed over five chemical transformations (four isolations). Uridine, an expensive material of limited availability, is the synthetic starting point, and the route suffers from low yield which occurs over the course of five chemical transformations (17\% maximum, yield of diol deprotection not disclosed).

Cytidine possesses the same ribose skeleton as uridine, yet it is less than half the price. Construction of the API from cytidine could lead to significant raw material savings as a result. We recently posted a communication which described a two-step route to MK-4482 from cytidine comprised of a hydroxyamination and esterification. ${ }^{3}$ The sequence of transformations can occur in either order, and esterification was achieved biocatalytically and also through classical chemical methods.

This strategy suffers from two drawbacks with respect to acylation. 1) The enzymatic route employs an expensive acyl donor (isobutyryl acetone oxime ester) which is added in excess to drive conversion. The cost of solid supported enzyme is also non-trivial. 2) The chemical acylation projects to be much less expensive; however, regioselectivity is not as high as the enzymatic route. Di, and tri-esterified by-products are observed in $>10 \%$, and because the route is so concise, purge of impurities could pose challenges. Continued development of alternative strategies are thus desired.

Synthesis of MK-4482 proceeding through the cytidine acetonide could be desirable for several reasons. First, it eliminates potential of undesired $O$-acylation, thus simplifying the impurity profile. This also enables the less expensive chemical esterification strategy. Lastly, the increased organic content might render intermediates more amenable to post reaction processing.

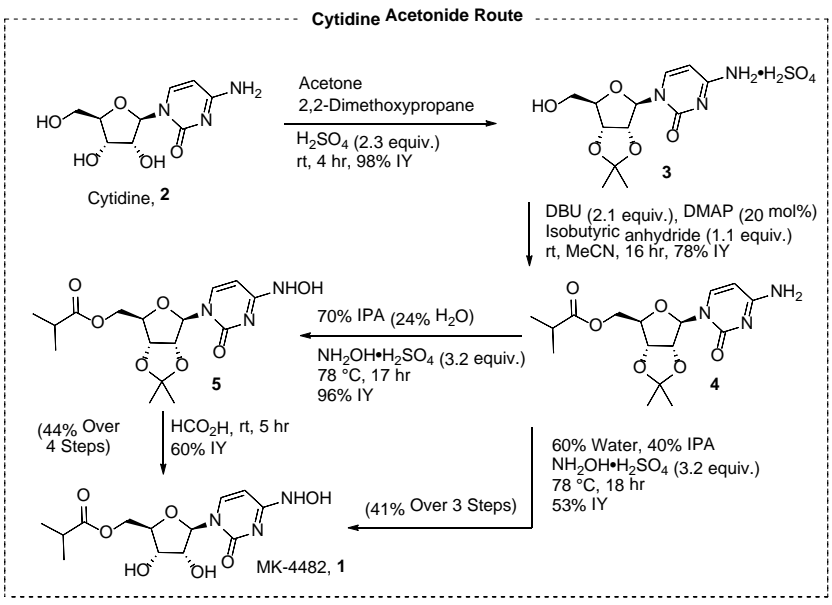

Figure 1: A new route to MK-4482 from cytidine.

Intermediates possessing the free diol are hydrophilic, and obtaining high recovery from aqueous layers can be challenging.

A route to MK-4482 proceeding through the acetonide was developed over the course of four chemical transformations (Fig. 1). Reaction of cytidine with acetone formed acetonide $\mathbf{3}$ in high yield (98\%). ${ }^{4}$ The product was isolated directly from reaction mixture in high purity as the sulfate salt. Acetonide ester $\mathbf{4}$ was obtained in good yield (78\%) with a slight modification of the reported procedure. ${ }^{5}$ Ability to successfully conduct direct transamination with hydroxylamine was key to unlock the route's potential, and critically, hydroxyamination proceeded without cleaving the isobutyryl ester. $N$-hydroxy ester 5 was isolated in excellent yield (96\%) while avoiding over addition on the cytosine ring. Removal of the acetonide protecting group led to MK-4482 in moderate yield (79\% AY, 60\% IY). Alternatively, hydroxyamination and acetonide cleavage could be performed in the same pot by simply extending the time of reaction; however, $\sim 20 \%$ of $N$-hydroxycytidine was formed as a byproduct.

These preliminary results demonstrate a route to MK-4482 making use of inexpensive cytidine. It negates the need for biocatalytic transformation and expensive oxime ester acyl donors, by improving feasibility of the chemical esterification. The overall yield is improved from $17 \%$ to $44 \%$, and a step is removed from the longest linear sequence. Future efforts will be directed toward optimization of the synthetic steps to render a process amenable route.

\section{ASSOCIATED CONTENT}

Supporting Information 
The Supporting Information is available free of charge on the ACS Publications website.

Experimentals (PDF)

Compound characterization (PDF)

\section{AUTHOR INFORMATION}

\section{Corresponding Author}

David R. Snead

737 N. $5^{\text {th }}$ St.

Box 980100

Richmond, Virginia 23298-0100

email: drsnead@vcu.edu

\section{Notes}

The authors declare no competing financial interests.

\section{ACKNOWLEDGMENT}

We thank the Bill and Melinda Gates Foundation for theirlongstanding support of our research. In addition, we express gratitude to Trevor Laird and John Dillon for their thoughtful commentary and discussion throughout this work. We also thank Silpa
Sundaram and Dr. Susan Hershenson for fostering a highly collaborative and dynamic ecosystem.

\section{REFERENCES}

1) a) Sheahan, T.P.; Sims, A.C.; Zhou, S.; Graham, R.L.; Pruijssers, A.J.; Agostini, M.L.; Leist, S.R.; Schafer, A.; Dinnon III, K.H.; Stevens, L.J.; Chappel, J.D.; Lu, X.; Hughes, T.M.; George, A.S.; Hill, C.S.; Montgomery, S.A.; Brown, A.J.; Bluemling, G.R.; Natchus, M.G.; Saindane, M.; Kolykhalov, A.A.; Painter, G.; Harcourt, J.; Tamin, A.; Thornburg, N.J.; Swanstrom, R.; Denison, M.R.; Baric, R.S. Sci. Transl. Med., 2020, 12, ASAP. b) Halford, B. "An emerging antiviral takes aim at COVID-19", Chem. Eng. News, 2020, 98. c) Cross, R. "Merck \& Co. joins race for COVID19 vaccines and therapies", Chem. Eng. News, 2020, 98.

2) a) Painter, G.R.; Bluemling, G.R.; Natchus, M.G.; Guthrie, D. WO2019113462, $2018 . \quad$ b) Painter, G.R.; Perryman, D.; Bluemling, G.R.WO2019173602, 2019.

3) Vasudevan, N.; Ahlqvist, G.P.; McGeough, C.P.; Paymode, D.J.; Cardoso, F.S.P.; Lucas, T.; Dietz, J.-P.; Opatz, T.; Jamison, T.F.; Gupton, B.F.; Snead, D.R., 2020, ChemRxiv preprint DOI 10.26434/chemrxiv.12818327.v1

4) Painter, G. R.; Guthrie, D. B.; Bluemling, G. R.; Natchus, M. G., WO2016106050A1, 2016.

5) Camacho-García, J.; Montoro-García, C.; López-Pérez, A.M.; Bilbao, N.; Romero-Pérez, S.; González-Rodríguez, D. Org. Biomol. Chem., 2015, 13, 4506-4513. 